\title{
United States Child Care Policy and Systems of Care: The Emerging Role of Quality Rating and Improvement Systems
}

\author{
Cynthia K. Buettner \\ David W. Andrews \\ The Ohio State University \\ USA
}

\begin{abstract}
The developmental and educational importance of high quality early care and education is well documented. The value of access to high quality care combined with the increasing demand for care has made access to high quality child care a central focus of U.S. public policy. State level licensure and national accreditation are the most prevalent strategies for promoting and assuring higher levels of care. More recently, Quality Rating and Improvement Systems (QRIS) have emerged as mechanisms for motivating child care professionals to provide higher quality care. QRIS systems are in their infancy, but are gaining popularity in several states. The future of these ratings systems will be determined by their predictive validity in improving observed levels of care, and ultimately in improved child outcomes. Strategically planned and rigorously designed research is needed to validate the use of these potentially effective rating systems.
\end{abstract}

Key words : quality, child care, policy

\section{Introduction}

The need to supply substitute care for parents who are working or otherwise unable to provide the care themselves has meant that young children in the United States are increasingly exposed to non-familial care and education prior to reaching kindergarten, the traditional start of formal schooling (National Association of Child Care Resource and Referral Agencies, 2007). This care and education is variously labeled as "child care", "early childhood education",

Correspondence concerning this article should be addressed to Cynthia K. Buettner, Assistant Professor, Department of Human Development and Family Science, 135 Campbell Hall, The Ohio State University, Columbus, $\mathrm{OH}$ 43210. Electronic mail may be sent to Buettner.16@osu.edu and "preschool". Regardless of the label, however, these services have become a primary source of basic care, developmental stimulation, and educational experiences for the majority of young children in the US.

At the same time, there has been a growing awareness that experiences in the early years sets a sound foundation for future development as the developmental, educational, and economic importance of the early years (infancy through preschool) has become increasingly clear over the past three decades. Emerging research on brain development indicates that early stimulation is critical in establishing the necessary neural pathways for optimal cognitive development. A summary of this research was released by the National Research Council and Institute of Medicine in from "Neurons to 
Neighborhoods" (Shonkoff \& Phillips, 2000) and generated new public interest in the conditions that are necessary to maximize stimulation in the early years. The reported studies suggested that early stimulation is critical to later high level cognitive functioning and that under-stimulated areas of the brain never fully develop.

Simultaneously, the educational and social benefits of high quality preschool education were promoted by the National Institute of Child Health and Human Development as a result of the longitudinal results of three major randomized clinical trials assessing the benefits of high quality early childhood education (National Institute of Child Health and Human Development Early Child Care Research Network, 2000, 2003). These three studies found significantly better adult outcomes (i.e., education completed, jobs attained, positive mental health outcomes) for those children who experienced high quality early childhood programs than those who did not.

Finally, Nobel Prize winning economist James Heckman conducted and released an analysis of the positive economic impact of providing high quality care and education during the early years (Heckman \& Masterov, 2007). His analysis suggested that investments in high quality early care and education yielded very high economic returns. The combined findings of this body of research stimulated a renewed national interest in assuring that children were receiving high quality care and education in the early years.

Ironically, the early child care and education system in the United States has historically been among the most informal and unregulated service delivery systems in the United States. For over a century, the US has developed ever more complex regulations and institutional controls in attempts to assure the quality of the more formal kindergarten through high school public system of education. Regulatory and support units were developed with copious effort and funding at the federal, state, and local levels resulting in a complex network of federal agencies, state departments of education, and local school districts. In comparison, systematic attention and oversight of the providers of care for young children in the US is in its infancy.

The United State's first formal and widespread program designed to meet the needs of socioeconomically disadvantaged children was introduced in 1965 with the creation of the Head Start program. The goal of this program was to provide early educational opportunities for preschool children in poor neighborhoods. However, these half-day programs were not designed to include high quality longer term child care that could assist working parents. The over reliance upon a programmatic approach to meeting the educational and developmental needs of low income children may have also impaired the expansion of national and local policies that would assure higher quality early care and educational experiences for all children.

Despite Head Start efforts, vast disparities in academic achievement related to the socioeconomic disadvantages of children continue to exist (Vinovskis, 1999). Given these pervasive disparities and the continued developments emphasizing the importance of early experiences in setting the developmental and educational trajectory of children, public system are emerging to promote and regulate high quality care and educational experiences for young children.

The predominant policies and practices related to high quality care have emerged from local and state level policies combined with standards set by national professional associations. Unlike the federally initiated No Child Left Behind Act of 2001, the predominant national reform effort in U.S. K-12 public education, assurances of high quality early care and education are being driven through local and statewide efforts. Interestingly, statewide systems focusing on high quality early childhood experiences are originating in both the child welfare and the educational arms of government.

The recognition that high quality early care and education is essential to later educational achievement 
and other positive developmental outcomes has created a sense of local urgency to improve access to quality care. The movement toward assuring access to high quality early care and education has developed around three quality assurance practices - licensure, accreditation, and quality rating systems.

\section{Licensure}

Typically, licensure systems are established by local and state governments to assure the quality of care provided to children. Research indicates that "regulatable" features of care are related to later child outcomes (Clarke-Stewart, Vandell, Burchinal, O'Brien, \& McCartney, 2002). The focus of licensure is often on the basic elements of safety and health. Licensure systems are most often grounded and administered in the state's child welfare branch of government. Licensure requirements vary from dramatically from state to state. Requirements typically include ratios of care providers to children, space requirements, and sanitation requirements.

Although every state has minimal requirements for licensure, these requirements vary greatly by state in both scope and coverage. Variability in scope implies that some states would require a wide array of rigorously monitored requirements for licensure, while others would take a minimalist approach with very few requirements and little monitoring. States also vary in which providers are required to be licensed. For example, states generally require centers serving larger numbers of children to be licensed. However, licensure requirements for family child care providers (caring for small numbers of children in the home) vary dramatically from state to state. Most states (34) require some form of licensure of family child care providers who care for at least four children. However, three states have no requirements for family child-care homes. Every state has more rigorous requirements for center-based care than they do for family based care.
Licensure has evolved as a primary effort to protect children from adverse care and to assure parents that basic levels of safety are being met. However, parents often do not understand licensure requirements and sometimes erroneously assume that all early childhood settings are licensed and are regularly inspected. Unfortunately, even in states with licensure requirements, licensing has not been used to establish the highest levels of care. The rising need for early care combined with the low wages received by child care providers mandates that entry level requirements are realistic and can be achieved by providers. Consequently, state licensure systems do not necessarily create greater availability of the highest levels of care. They typically set a minimal standard that can be reached by enough providers to assure affordable access.

\section{Accreditation}

Recognizing the need to stimulate greater access to high quality early care and education, key professional organizations in early childhood developed accreditation systems that encourage their members and others in the early childhood professional community to implement higher quality programs based upon a professionally agreed upon set of program standards. The National Association for the Education of Young Children (NAEYC) and the National Association of Child Care Resource and Referral Association. (NACCRA) have established the most widely used and respected systems of accreditation currently being used in the United States.

Accreditation systems developed by professional associations such as NAEYC and NACCRA incorporate the highest standards of care. However, achieving these standards requires considerable effort, both in developing a high quality program and in completing the review process for accreditation. For example, NAEYC accreditation requires a somewhat lengthy self-evaluation followed by a waiting period 
prior to a formal review visit. The entire process can take one to two years. Given the rigor of these accreditations and the stamina that is required to complete the process, relatively few child care sites have opted for accreditation. Less than $10 \%$ of all child care centers in the United States are accredited (National Association of Child Care Resource and Referral Agencies, 2007; the exception being centers on U.S military basis where all centers are required to be accredited or to be moving toward accreditation).

Unlike licensure, where minimal requirements for health and safety are the norm across different state licensure systems, national accreditation sets very high standards for quality across multiple areas within the child care domain. National accreditation systems address health and safety, but also include assessments of developmentally pertinent issues such as personnel qualifications and training, educational pedagogy, child guidance practices, and parent involvement.

The rigor of national accreditation systems render them infeasible to many child care providers. Incentives for achieving accreditation may not always justify the investment. Most parents are not well informed about the potential benefits of having their children in accredited centers. If the cost of meeting accreditation requirements increases the cost of care to parents, they may not see the benefits of the added expense. Although some states have implemented or are contemplating policies that provide incentives for accreditation, accredited centers do not uniformly qualify for additional subsidies.

\section{Quality Rating Systems}

Quality Rating Systems (QRS), also referred to as Quality Rating and Improvement Systems (QRIS), are emerging in many states as a mechanism for identifying and promoting higher quality care. Rating systems are developed using a set of quality indicators that range from meeting basic requirements (e.g., licensure requirements) and progress through multiple levels of quality toward the highest professional standards (often national accreditation). They are designed to improve child-care quality by defining quality standards, educating consumers and providers on program quality, and providing incentives and support for quality improvement (Zellman, Perlman, Le, \& Setodji, 2008, p.25).

Quality Rating Systems typically use some sort of symbol to indicate the level of quality associated with a particular assessment system. The most common symbol is a star. Consequently, rating systems are sometimes referred to as "star rating systems." In a typical star system, one star would indicate that a program meets acceptable standards, two stars would indicate even higher quality, and three stars would indicate the highest level quality of care.

Referring to these systems as Quality Rating and Improvement Systems (QRIS) is gaining popularity among professionals and state policy makers who recognize that one of the most important benefits of rating systems is the incentive that they offer child care providers to improve their quality of early care and education. In this sense, rating systems are used as formative assessments to provide feedback on how childcare providers and early childhood educators can improve their programs, rather than summative evaluations that are used solely for the purpose of classifying and judging the current quality of a program. QRISs have also experienced increasing popularity because they are a straightforward way to improve child-care quality without investments of large amounts of capital. The number of states implementing some form of rating system has increased from 14 in early 2006 to 36 at the beginning of 2008 (Zellman, Perlman, Le, \& Setodji, 2008, p. 31).

QRISs are expected to improve child outcomes by improving child-care environments. The theory underlying the QRIS logic model conjectures that as parents learn about ratings, they will use the ratings to influence their selection choice. Programs will then improve to remain competitive, leading to more 
higher-quality choices, thus leading to improved cognitive and emotional outcomes.

Research on QRSs and QRISs is limited in both focus and depth. Empirical support for measures of child-care quality in general is inadequate (Zellman, Perlman, Le, \& Setodji, 2008, p. 27) and may hinder relationships between rating systems and child outcomes. To date, evaluations on rating systems generally have focused on the relations between ratings and environment rating scales (ERSs) to assess the validity of the rating system (Zellman, \& Perlman, 2008). Few relationships between rating systems and child outcomes have been examined.

In one of the first efforts to evaluate QRISs the RAND Corporation evaluated Colorado's QRIS, Qualistar. Their evaluation found no significant relationships between "process measures" and the star rating or child outcomes. Process measures are the measures relating to the quality of child-staff interactions and instruction. There were a few relationships found between individual QRIS components and child outcomes, although none were strong. There were no relationships found between overall star ratings and child outcomes (Zellman, Perlman, Le, \& Setodji, 2008).

A subsequent report from the Rand Corporation evaluated the implementation of QRiS systems in four additional U.S. states (North Carolina, Ohio, Oklahoma, and Pennsylvania). Each state is in the process of conducting its own evaluation of newly implemented rating systems. States are finding validation for their systems in results indicating that higher rated programs demonstrate improved scores on independently measured dimensions of quality. There is, however, no current evidence that quality rating and improvement systems are leading to improved child outcomes.

The Rand report concludes that it may be expecting too much to find effects on measures of cognition, peer relationship problems, or pro-social behavior (Zellman, \& Perlman, 2008, p. 103) from the quality of child-care only. However, the report acknowledges a dearth of high quality research in this area. The lack of high quality research can be attributed to general measurement limitations related to congruous identification of high quality interactions and care, as well as the relatively new accountability expectations associated with early care and education. The report advocates for more high quality research prior to making final judgments about the contributions of rating systems.

Although necessary to maintain funding, it may be premature to conduct research on the child outcomes associated with specific provider ratings. Quality rating systems are new and best practices for developing and implementing such system are currently being articulated. The Rand report is among the first article to articulate best practices associated with QRIS in early childhood. The report identified the following critical elements of a well functioning QRIS.

1. Adequate Funding: Implementing, monitoring, and incentivizing rating systems requires adequate funding and sustainable fiscal support.

2. Sufficient Marketing and Public Awareness: Providers and parents must be made aware of the system and its benefits.

3. Availability of Technical Support: Child care providers must be supported in their application efforts and provided feedback as it relates to program improvement.

4. Appropriate Structure and Oversight: The appropriate infrastructure, policies, and procedures must be in place to allow monitoring and oversight of the system.

Sound program development and evaluation principles suggest that it is essential to assure that programs are being implemented as designed and with high fidelity prior to the conduct of rigorous summative evaluations of impact. Assuring that best practices are in place prior to launching comprehensive outcome studies is essential to avoiding the premature termination of rating systems 
due to false non-findings.

The initial focus of future research should be on the role of rating systems in stimulating an increase in the availability of high quality care. The relationship between high quality care and positive child outcomes has been well established. The question then is, "do Quality Rating and Improvement Systems lead to the availability of higher quality care?" Adequately addressing this question requires improved measurements of "quality" and sufficiently broad, holistic analyses of child outcomes.

Rating systems in various states are largely voluntary. However, in some states and local implementations, higher ratings carry additional incentives in the form of public financial support and subsidy. If statewide funds currently being used to support quality rating and improvement systems are to be maintained, it will become increasingly important to document the relationship between rating systems and access to high quality care. Such documentation is being attempted in a limited number of states.

For example, Ohio is currently conducting a large scale study of over 4000 children who are receiving care in more than 400 centers. This study will eventually target the anticipated positive child outcomes associated with receiving a prescribed level of care. However, the first phase of the study is to create and test the appropriate measurement constructs to assess high quality care, and the second phase of the study is designed to assess the relationship between rating level and the quality of care being received. The relationship between quality rating level and positive child outcomes will be assessed in the final phase of the project.

The Rand report suggests that QRISs are "highstakes" evaluation activities, the results of which can directly influence the future of a program.

Many of the measures used to assess the components were developed in low-stakes settings, such as research studies or self assessments, where there were few, if any, consequences attached to a particular score.
These measures may not be appropriate in high-stakes settings, where scores could substantially affect a program's bottom line (American Educational Research Association, American Psychological Association, \& National Council on Measurement in Education, 1999). At the very least, such studies must be conducted; they may show that new measures need to be developed. Some quality components, such as parent involvement, have not been subjected to careful empirical assessment. Nor has the way in which components are weighted and combined into summary measures been studied.

Additional research on QRIS is warranted and should be strategically planned and conducted. The initial rationale for implementing QRIS is to enhance the quality of accessible care. The assumption is that the resulting access to high quality care is associated with future positive child outcomes. While this assumption must be eventually tested, this level of research is irrelevant if there is no connection between QRIS and improved access to high quality care.

\section{Summary and Policy Implications}

The importance of providing high quality nonfamilial care and education to young children has been clearly articulated in research and is being addressed in emerging policy. Sound research has linked high quality education and care to later educational and developmental outcomes. Furthermore, socioeconomically disadvantaged children need the stimulation afforded by such care and education in order to learn and develop on par with their more economically advantaged peers. The educational and developmental necessity of high quality child care in the early years has spawned public efforts to promote greater access.

Within the United States, federal guidelines and policy support for a uniform public system of education have improved in the past few decades. States continue to vary rather dramatically in the 
quality of their public educational systems, yet most would agree that each state has a "system" of public education designed to address the needs of children starting in kindergarten and progressing through higher education. Early childhood professionals argue that the United State as a whole has not developed a system of child care. Furthermore, very few states have what would be considered a robust system of care. Noted child care advocate and scholar Sharon Kagan refers to the U.S. approach to child care as "a non-system of microenterprises" (Kagan, 2008).

In lieu of a complete system of care, state governments have historically relied upon licensure to assure baseline levels of quality. Given their protective mission, most governmental agencies have adopted a "do no harm" approach to licensure. Inversely, professional associations in early childhood have embraced a mission to identify the highest levels of quality and to accredit sites who are able to reach these high standards. The result is a very uneven distribution of accessible quality.

Quality Rating and Improvement Systems (QRIS) represents an emerging approach that has the potential to continually grow the availability of high quality early care and education sites. The promise is in creating a structure that motivates continuous improvement through the belief that consumers (parents) will chose care that is highly rated. Focusing on formative assessments and feedback related to "Improvement" of quality is a cornerstone of the approach.

QRIS systems will survive if credible documentation exists that such systems improve access to high quality education and care. QRIS systems will thrive if documentation exists that such systems not only improve access to high quality care and education, but that these systems also lead to more positive child outcomes. Future research should focus on 1) better understanding the relationship between QRIS systems and access to high quality education and care, and 2) better understanding the role of QRIS systems in promoting more positive child outcomes. A central component of this research is to refine and improve measurements of high quality care and education. Consensus on operational definitions of high quality care, followed by the creation of reliable metrics aligned with these definitions will be required.

Many states are cautiously, yet optimistically, exploring the implementation of rating systems to promote higher quality early care and education. Additional research is necessary to better inform policy decisions related to implementation of these rating systems. In addition, states should continue to monitor the efforts, successes, and challenges of others to better inform their decisions.

\section{References}

American Education Research Association, American Psychological Association, \& National Council on Measurement in Education. (1999). Standards for educational and psychological testing. Washington, DC: American Educational Research Association.

Clarke-Stewart, K. A., Vandell, D. L., Burchinal, M., O'Brien, M., \& McCartney, K. (2002). Do regulable features of child-care homes affect children's development? Early Childhood Research Quarterly, 17(1), 52-86.

Heckman, J. J., \& Masterov, D. V. (2007, April). The productivity argument for investing in young children (NBER working paper No. W13016). Retrieved July 6, 2009, from http://www.nber.org/ papers/w13016

Kagan, S. L. (2008, June). Buckets, banks, and hearts: Aligning early childhood standards and systems. Paper presented at the Quality Rating and Improvement Systems: Creating the Next Generation of QRISs conference, St. Paul, MN.

National Association of Child Care Resource and Referral Agencies. (2007, June). Threshold of licensed family child care. Retrieved July 28, 2008, from http://www. naccrra.org/randd/licensing 
_training_qr/fcc_threshold.php

National Institute of Child Health and Human Development Early Child Care Research Network. (2000). The relation of child care to cognitive and language development. Child Development, 71(4), 960-980.

National Institute of Child Health and Human Development Early Child Care Research Network. (2003). Does quality of child care affect child outcomes at age 41/2? Developmental Psychology, 39(3), 451-469.

Shonkoff, J., \& Phillips, D. (2000). From neurons to neighborhoods, Washington, DC: National Academy Press.
Vinovskis, M. (1999). Do federal compensatory education programs really work? A brief historical analysis of Title I and Head Start. American Journal of Education, 107(3), 187-209.

Zellman, G. L., \& Perlman, M. (2008). Child-care quality rating and improvement systems in five pioneer states: Implementation issues and lessons learned. Retrieved July 6, 2009, http:/ / from www.rand.org

Zellman, G. L., Perlman, M., Le, V. N., \& Setodji, C. M. (2008). Assessing the validity of the Qualistar early learning quality rating and improvement system as a tool for improving child-care quality. Retrieved July 6, 2009, from http://www.rand.org 